\title{
Pragmatism as a Supportive Paradigm for the Mixed Research Approach: Conceptualizing the Ontological, Epistemological, and Axiological Stances of Pragmatism
}

\author{
Heba Maarouf ${ }^{1}$ \\ ${ }^{1}$ Business Administration Department, Faculty of Commerce, Cairo University, Egypt \\ Correspondence: Heba Maarouf, Business Administration Department, Faculty of Commerce, Cairo University, \\ Giza, 12631, Egypt.
}

Received: July 8, 2019

Accepted: July 29, 2019

Online Published: August 26, 2019

doi:10.5539/ibr.v12n9p1

URL: https://doi.org/10.5539/ibr.v12n9p1

\begin{abstract}
The emergence of the mixed research approach has been accompanied by searching for a philosophy that legitimates mixing quantitative and qualitative methods in one research. Many researchers consider pragmatism as the most common philosophical justification for the mixed research approach; however, pragmatism is criticized as a philosophy in general and also as philosophical support for the mixed research approach especially for not addressing the differing assumptions of the quantitative and qualitative paradigms. Trying to overcome this criticism, the current research is mainly concerned with presenting pragmatism as a coherent, integrated paradigm by conceptualizing its ontological, epistemological and axiological stances. The researcher coins three new terminologies: the reality cycle, the double-faced knowledge, and the necessary bias principle. These philosophical stances combine both the quantitative and qualitative paradigms' points of view as two integrated, not conflicting philosophies.
\end{abstract}

Keywords: pragmatism, mixed research, the reality cycle, the double-faced knowledge, the necessary bias principle

\section{Introduction}

The quantitative and qualitative paradigms face one another in a long-lasting debate or what so-called "the paradigm war". It has started at the '70s and continued through the '80s and the '90s (Hall, 2013; Johnson \& Christensen, 2012; Sale, Lohfeld, \& Brazil, 2002). During the '80s each group of researchers claimed that their approach is superior and some of them were "purists" assuring that the quantitative and qualitative approaches cannot be combined together because of the quantitative-qualitative paradigmatic differences, what is known as the "incompatibility thesis". Starting from the '90s many researchers have refused this principle and started a new approach mixing quantitative and qualitative research methods (Biddle \& Schafft, 2015; Glogowska, 2011; Johnson \& Christensen, 2012; Johnson \& Onwuegbuzie, 2004).

Gradually, the adaptation of the mixed research approach has incredibly increased. In 2013, nearly 1800 mixed methods studies were published, this is a huge jump compared to nearly 20 articles per year in the '90s. This dramatic increase has been "professionally legitimatized" by textbooks and journals that are mainly concerned with mixed research (Biddle \& Schafft, 2015; Molina-Azorin, 2016) such like "Journal of Mixed Methods Research". Moreover, the mixed research approach is spreading in many research disciplines including for example business research, psychology, sociology (Molina-Azorin, 2016), international relations (Pratt, 2016), educational research (Johnson \& Christensen, 2012), library and information sciences research (Ma, 2012), information system research (Goldkuhl, 2008, 2012), and health service research (Glogowska, 2011; Sale et al., 2002). However, Barnes (2019) believes that the mixed research approach is not sufficiently represented in the social sciences until the moment taking into account the rich and valuable insights that it provides.

Scholars suggested many different philosophies to justify the mixed research approach (Barnes, 2019; Fetters and Molina-Azorin, 2017b; Ghiara, 2019). Between all these philosophies, pragmatism is considered by many researchers to be the most common philosophical justification (Biddle \& Schafft, 2015; Dieronitou, 2014; Hall, 2013; Hathcoat \& Meixner, 2017; Yvonne Feilzer, 2010). However, pragmatism is criticized as a philosophy in general and also as philosophical support for the mixed research approach especially for not addressing the 
differing assumptions of the quantitative and qualitative paradigms (e.g., Hall, 2013; Biddle \& Schafft, 2015; Sale et al., 2002). Trying to overcome this criticism, the current research is mainly concerned with presenting pragmatism as a coherent, integrated paradigm by conceptualizing its ontological, epistemological and axiological stances in a way that combines both quantitative and qualitative paradigms' points of view as two integrated, not conflicting philosophies.

The present research is organized as follows. First, differentiating between the quantitative and qualitative research paradigms and approaches. Second, explaining the mixed research approach and the philosophical debate around it. Third, discussing pragmatism as the most common philosophical justification for the mixed research approach and explaining some aspects of criticism it faces. Forth, conceptualizing the ontological, epistemological and axiological stances of pragmatism. The researcher coins three new terminologies: the reality cycle, the double-faced knowledge, and the necessary bias principle. Finally, the research contribution and conclusion are summarized.

\section{Quantitative and Qualitative Research Paradigms and Approaches}

The quantitative paradigm is based on objectivism and positivism, therefore, it is called "the scientific research" (Creswell, 2014; Ma, 2012; Jonker \& Pennink, 2010). According to the quantitative paradigm, there is only one objective reality that is separated from the researcher's perceptions. The researcher is independent of the phenomenon under investigation, he does not affect nor affected by the phenomenon. The main goal of quantitative research is to measure causal relationships using a value-free framework (Johnson \& Onwuegbuzie, 2004; Sale et al., 2002). From the other hand, the qualitative paradigm is based on subjectivism and interpretivism. Qualitative researchers believe in the existence of multiple realities based on researcher's construction of reality. The investigator and the phenomena cannot be separated and findings are mutually created within the context through value-bound research, which suggests that reality does not exist before the investigation process and ceases to exist when we no longer focus on it (Johnson \& Onwuegbuzie, 2004; Sale et al., 2002).

The quantitative approach follows the quantitative research paradigm and depends on the collection and analysis of quantitative data (Bryman \& Bell, 2007; Johnson \& Christensen, 2012). It is a "confirmatory" or a "deductive" approach as its main goal is to test theories and hypothesis by examining the relationships among variables (Antwi \& Hamza, 2015; Bryman \& Bell, 2007; Johnson \& Christensen, 2012; Creswell, 2014). On the other hand, the qualitative approach follows the qualitative research paradigm and depends on the collection and analysis of qualitative data (Bryman \& Bell, 2007; Johnson \& Christensen, 2012). It is an "exploratory" or an "inductive" approach that aims to explore and understand the meanings that individuals or groups attach to the social phenomena (Bryman \& Bell, 2007; Johnson \& Christensen, 2012; Creswell, 2014).

However, many researchers believe that both approaches can be integrated to serve the process of social inquiry for two reasons. First, the choice between the quantitative and qualitative research approaches is mainly based on the position of the conducted research to the theory. The quantitative deductive approach is testing a theory, while the qualitative inductive approach is developing one (Glogowska, 2011; Saunders, Lewis, \& Thornhill, 2009). Second, besides the role of each approach in developing knowledge, the two approaches have contradicting advantages and disadvantages. The quantitative approach has the advantages of providing quantitative precise results and being relatively quicker in data collection and analysis. However, theory and hypotheses tested in the quantitative research may disregard some important variables and do not reflect the local social understanding. From the other side, qualitative research is useful in examining a limited number of cases in depth. It is also very helpful in addressing complex phenomena as it can provide rich details. However, the knowledge produced by qualitative research cannot be generalized in other contexts. Besides, it is very time-consuming in data collection and analysis (Johnson \& Onwuegbuzie, 2004). From this integrated view of the quantitative and qualitative research, the mixed research approach has emerged

\section{The Mixed Research Approach}

\subsection{Defining the Mixed Research Approach}

Over the past two decades, the mixed research approach has been increasingly acknowledged as the third methodological movement (Biddle \& Schafft, 2015; Cameron, 2011; Hall, 2013; Ma, 2012; Molina-Azorin, 2016). Quantitative and qualitative approaches are no longer seen as two discreet opposite approaches. Instead, they represent two ends of a continuum as a study can be seen as more quantitative than qualitative or vice versa. The mixed research approach is in the middle of this continuum (Creswell, 2014; Johnson \& Onwuegbuzie, 2004). 
In the mixed research, a researcher uses a mix of quantitative and qualitative approaches (designs and methods) in one study or a set of related studies. This can be done either concurrently when conducting both parts at the same time or sequentially when conducting one part first and the other second (Antwi \& Hamza, 2015; Johnson \& Christensen, 2012; Ma, 2012; Molina-Azorin, 2016). The reason for choosing the methods will determine its order in the research design (Glogowska, 2011; Molina-Azorin, 2016). The core assumption of the mixed research approach is that mixing quantitative and qualitative methods provides a complete understanding of the research problem than using only one type of methods (Creswell, 2014; Molina-Azorin, 2016). For example, Mitchell (2018) have explained two case studies where mixed research methods were used, he found out that using mixed research have provided both quantitative and qualitative reasoning that lead to best data explanation and best understanding for the studied research phenomena.

The mixed research approach is usually referred to as the "mixed methods research". However, researchers are arguing about which term is more appropriate. For example, Johnson \& Christensen (2012) believe that using the term "mixed research" without including the word "methods" is not only simpler but also more accurate as the quantitative-qualitative debate is not only about methods but mainly about philosophy. However, Fetters and Molina-Azorin, (2017b) disagree arguing that when the term "mixed methods research" was initiated there was no intention to exclude the philosophical aspects of the concept, and meanwhile, the term is seen to be inclusive of all philosophical and methodological sides. Although the term "mixed methods research" is the most commonly used at the present time (Johnson, Onwuegbuzie, \& Turner, 2007), the researcher agrees with Johnson and Christensen and believes that the term "mixed research" is what actually reflects the true essence of this approach.

In addition, the mixed research approach is different than what is called the "multi-methods approach" or "multiple methods approach". However, the relationship between the two terms is not clear. For example, Greener (2008) and Hall (2013) believe that in the multiple methods approach a researcher adopts different methods of data collection that all belong to the same type either quantitative or qualitative, subsequently; it does not face the same philosophical debate the mixed research approach does. On the contrary, Fetters and Molina-Azorin, (2017a) believe that the multiple methods approach includes using more than one method of data collection that can be all quantitative, all qualitative or a mix of quantitative and qualitative methods; in consequence, they classify the mixed research approach as one form of the multiple methods approach.

Finally, it worth mentioning that some researchers refer to the mixed research as a third paradigm or a combination of paradigms, not as a third approach (e.g., Baŝkarada and Koronios, 2019; Ghiara, 2019; Ma, 2012). Researchers who adopt this point of view explain their perspective by the various meaning of the term paradigm itself. In the researcher's opinion, this is an additional source of confusion that we do not need. It is necessary to differentiate between mixing quantitative and qualitative methods as a research approach and the underlying philosophical assumptions that support this methodological choice.

\subsection{Advantages and Challenges of the Mixed Research Approach}

There are two main advantages of using the mixed research approach (Sale et al., 2002). The first advantage is the "complementary strengths" which means using the strengths of one research method to enhance or support another one. Mixed researchers believe that using only quantitative or qualitative research is limited and incomplete for many research problems. As every approach has its strengths and weaknesses; they should be combined in a way that improves research quality by gaining integral strengths and avoiding overlapping weaknesses (Johnson \& Christensen, 2012; Sale et al., 2002).

The second advantage is "Triangulation". The purpose of triangulation is to enrich and strength research results by using different methods of data collection and analysis to study the same phenomenon in order to gain a complete understanding of this phenomenon. Triangulation is also used to check on findings from a particular method with finding reached by another one (Glogowska, 2011; Greener, 2008; Molina-Azorin, 2016; Sale et al., 2002).

From the other side, implementing the mixed research approach is faced by two main challenges. First, the mixed research approach needs more time, effort, and money as it includes two phases of research at least (Molina-Azorin, 2016). Second, it requires the researcher to expand his research skills, talents and experiences by learning about new research methods and techniques in order to be qualified to conduct both the quantitative and qualitative parts of research (Fetters and Molina-Azorin, 2017b; Molina-Azorin, 2016). This last challenge, in particular, should be seen as an opportunity, as many researchers tend to keep using the same research methods and avoid learning about new ways of doing research which limits their chances of adopting a wide range of research problems (Molina-Azorin, 2016). 


\subsection{Research Designs for the Mixed Research Approach}

There are three research designs for the mixed research approach. First, the "convergent parallel mixed method" is a research design where a researcher collects both quantitative and qualitative data at the same time and then integrates the overall results to get comprehensive analysis for the research problem (Barnes, 2019; Creswell, 2014). This research design can take two forms, "the concurrent triangulation design" which uses two research methods one of them is basically used to confirm or check on the findings of the other, and the "concurrent nested design" where there is one main research method and the other one is used for different purpose such as answering a different research question or focusing more on a minor group of a major group (Barnes, 2019)

Second, the "explanatory sequential mixed method" is a research design where a researcher conducts quantitative research first then qualitative research. The researcher conducts the qualitative research to provide further explanation for the quantitative research results. Finally, there is the "exploratory sequential mixed method" where a researcher starts with qualitative research then conducts quantitative research. Data from the qualitative phase could be used to build a new instrument, choose an appropriate one, or to choose variables that are going to enter the following quantitative research phase (Barnes, 2019; Creswell, 2014).

\subsection{The Philosophical Debate Around the Mixed Research Approach.}

The emergence of the mixed research approach has been accompanied by searching for a philosophy that legitimates mixing quantitative and qualitative methods in one research (Biddle \& Schafft, 2015; Johnson et al., 2007; Hall, 2013). Researchers have used different approaches and suggested different philosophies to deal with this dilemma. Three different approaches are dealing with the philosophical debate around the mixed research approach: the paradigmatic stance, the multiple paradigm approach, and the single paradigm approach (Barnes, 2019; Hall, 2013).

"The paradigmatic stance" is simply ignoring the quantitative-qualitative debate completely based on the idea that methodology is independent of epistemology (Barnes, 2019; Hall, 2013). If we argue that choosing research methods does not depend on paradigms, this means that both quantitative and qualitative methods can be used under any research paradigm (Mkansi \& Acheampong, 2012; Saunders et al., 2009). However, the relationship between methods and paradigms is complicated and not agreed upon. For example, Betzner (2008) and Johnson and Onwuegbuzie (2004) believe that although some methods are best used under a certain paradigm, it does not mean that the relationship is constant as many research methods can be used under both the quantitative and qualitative paradigms. On the other hand, Hall (2013) disagree with this notion and asserts that epistemology constrains what can be considered valuable knowledge and, in consequence, methods of collecting and analysing this knowledge.

While the previous approach ignoring the paradigmatic debate, "the multiple paradigm approach" claims that paradigms are not incompatible, thus quantitative and qualitative methods can be used in one research (Hall, 2013). According to this approach, although every type of methods belongs to a different paradigm, combining quantitative and qualitative methods is too valuable for generating different type of contributions in research (Barnes, 2019). For example, Mitchell (2018, p. 104) have stated that "quantitative and qualitative research approaches are not only compatible but also complementary". The same meaning has been expressed by Weber (2004) as he has mentioned that the quantitative-qualitative debate is no longer useful or helpful and differences between the two paradigms are shallow and not real, and even if differences between paradigms are true, they have little impact on how excellent researcher do their job as they simply choose research methods that best serve their research objectives.

These two approaches, the paradigmatic stance and the multiple paradigm approach, give the impression that mixed research has no philosophical justification. For example, Sale et al. (2002) believe that the mixed research approach is adopted by a new generation of researchers who do not acknowledge the philosophical distinctions between the two paradigms. Instead, they recognize the technical differences and believe that quantitative and qualitative techniques are just tools that can be integrated to answer critical research questions. Sale et al. have criticized the non-philosophical arguments imposed to justify the mixed research approach such like that both paradigms share the same goal of understanding the world, both include the belief of theory representation of facts, and combining the two paradigms is very useful in studying complex phenomena. They believe that these arguments are not enough as none of them addressing the underlying assumptions for every paradigm and challenging these assumptions is the only convincing way of combining the two paradigms in one research.

The critics directed to the previous approaches have created "the single paradigm approach" which asserts that both quantitative and qualitative methods can be combined under a single paradigm (Barnes, 2019; Hall, 2013). The question remains, which one? 
Researchers have suggested different paradigms that would serve as the philosophical background of the mixed research approach (Barnes, 2019; Fetters and Molina-Azorin, 2017b; Ghiara, 2019). These suggestions include "pragmatism", "critical realism", the "transformative" paradigm, (Fetters and Molina-Azorin, 2017b; Ghiara, 2019; Shannon-Baker, 2016), dialectical pluralism (Barnes, 2019; Fetters and Molina-Azorin, 2017b; Shannon-Baker, 2016), postmodernism (Fetters and Molina-Azorin, 2017b), feminism and realism (Barnes, 2019; Ghiara, 2019). However, Pragmatism is considered by many researchers as the most common philosophical support for the mixed research approach (Biddle \& Schafft, 2015; Dieronitou, 2014; Hall, 2013; Hathcoat \& Meixner, 2017; Yvonne Feilzer, 2010).

\section{Pragmatism as a Philosophical Justification for the Mixed Research Approach}

Many researchers have stressed that pragmatism can provide a philosophical justification for the mixed research approach. For example, Denscombe (2008) and Mitchell (2018) have mentioned that pragmatism is considered to be "the philosophical partner" of the mixed research approach as its underlying assumptions provide the essence for mixing research methods. Also, Johnson et al. (2007) agree that pragmatism is an advanced philosophy that provides the epistemology and the logic for combining the quantitative and qualitative approaches and methods. Moreover, Creswell (2014) has mentioned that pragmatism is the philosophy that permits mixing paradigms, assumptions, approaches and methods of data collection and analysis.

Pragmatism is all about the notion "what works". This is mainly referring to the pragmatic theory of truth. Pragmatism is simply oriented toward solving practical problems in the real world rather than being built on assumptions about the nature of knowledge (Creswell, 2014; Hall, 2013; Shannon-Baker, 2016). This means that pragmatism leads "action-oriented" research procedures (Cameron, 2011).

In order to explain the relationship between knowledge and action from the pragmatic point of view, Goldkuhl (2008) and (2012) has defined three forms of pragmatism. First, the "functional pragmatism" or "knowledge for action" which means that the purpose of scientific knowledge is to improve action and make a practical difference. Second, the "referential pragmatism" or "knowledge about action" which implies that pragmatism describes the world in an action-oriented way. Third, the "methodological pragmatism" or "knowledge through action" which asserts that knowledge is created through action, or action is our source to know about the world.

In addition, the notion "what works" is also related to the use of research methods (Creswell, 2014; Hall, 2013). Every research starts with an interesting thought or a research question and a final goal to answer this question in order to add valuable knowledge to the concerned area of research (Greener, 2008). According to pragmatism, research should be designed and conducted in the best way that serves to answer the research questions regardless of its underlying philosophy (Biddle \& Schafft, 2015; Creswell, 2014; Glogowska, 2011; Johnson \& Christensen, 2012; Saunders et al., 2009).

As it supports using whatever research method "works" to answer the research questions, pragmatism does not only justify the mixed research approach but also opens all methodological choices in front of a researcher where the mixed research approach becomes one way of applying the pragmatic philosophy. Biddle \& Schafft (2015) have mentioned that a pragmatic researcher has the option to conduct quantitative, qualitative or mixed research based on what serves his research purposes.

Many researchers criticize pragmatism as a philosophy in general and also as a philosophical justification for the mixed research approach. In the researcher's opinion, some of these arguments are not strong enough while others cannot be ignored. For example, Hall (2013) has criticized pragmatism from a methodological point of view for not defining "what works" when it comes to research methods. He has argued that the value of research methods cannot be assessed before the research is completed. However, the researcher believes this argument is not convening. The purpose, advantages, and disadvantages of every research method are clear and have been examined by thousands of researchers. The talent of a pragmatic researcher relies on his ability to determine which research method serves which research purpose and in case of mixing methods he should be able to design his research in a way that gains the advantages of both quantitative and qualitative methods while avoiding their weaknesses. Another example, Biddle \& Schafft (2015) have criticized pragmatism from an axiological point of view. They have argued that pragmatic researchers ignore the role of values in research. They suggest that defining pragmatism as "what works" raises the question of "what works for whom and to what extent? The researcher believes this is a week argument too. One possible simple answer for the question "what works for whom?" it could be anyone the pragmatic researcher is interested to serve by his research based on whatever research purposes he decides.

However, pragmatism also faces strong criticism for its basic underlying assumptions. For example, Biddle and Schafft (2015) have criticized pragmatic researchers for using any research method believing that the philosophy 
which a research method is based on is not related to the practical benefits of this method. In addition, Sale et al. (2002) argue that pragmatism does not address the issue of the differing assumptions of the quantitative and qualitative paradigms. They believe these assumptions suggest that quantitative and qualitative methods are not studying the same phenomenon, which makes mixing methods for cross-validation or triangulation is not logical.

In the researcher's opinion, this is the strongest criticism for pragmatism as a philosophy in general and a justification for the mixed research approach. The researcher believes that the philosophy which any research method is based on and the practical benefits of this method are totally related, however, pragmatic researchers did not give much attention to the paradigmatic philosophical debate depending heavily on the notion "what works". Without a clear philosophical justification for the pragmatic methodological choices, pragmatism will always be underestimated as an integrated paradigm and will be equal to "the paradigmatic stance" or "the multiple paradigm approach". Therefore, the researcher is presenting pragmatism as a coherent paradigm by conceptualizing its ontological, epistemological, and axiological stances from her point of view.

\section{Conceptualizing the Philosophical Stances of Pragmatism:}

As it has been explained, without philosophical justification for the mixed research approach, we have two options, either to ignore the quantitative-qualitative debate completely or pretend that the two paradigms are not incompatible. Both options are desperate solutions for not challenging the differing assumptions of the quantitative and qualitative paradigms and will always be criticized.

Mixed researchers need to state their philosophical or paradigmatic stances clearly in order to be able to justify their methodological choices (Cameron, 2011). Given this necessity, the researcher conceptualizes the ontological, epistemological and axiological stances for pragmatism in a way that combines both the quantitative and qualitative paradigms' points of view as two integrated, not conflicting philosophies.

By clarifying these stances, the researcher believes that pragmatism can serve not only as the philosophical partner for the mixed research approach but also as the paradigm that has the potentials to win the "paradigm war" by ending the quantitative-qualitative paradigms debate. Pragmatism is the paradigm that opens all possible options in front of a researcher, what can make it prevail over all other research philosophies.

\subsection{The Ontological Stance: The Reality Cycle}

Based on the principle of the "ontological foundationalism" a researcher needs to have a clear view about reality or he will not be able to make the right methodological choices (Lohse, 2016). However, ontology is the most ignored aspect of the pragmatic philosophy as pragmatism is usually seen as epistemological and methodological stances, not as a whole integrated paradigm.

Many researchers have referred to the importance of dealing with the ontological differences between the two paradigms for pragmatism. Morgan (2007) has argued that pragmatism implies that pragmatic research is "intersubjective" which means being subjective and objective at the same time, accepting both the existence of one reality and that individuals have multiple interpretations of this reality. Moreover, Saunders et al. (2009) have mentioned that pragmatism implies that reality is external and multiple at the same time and that a researcher chooses the view best serves his research purposes. Similarly, Johnson and Christensen (2012) have mentioned that to conduct mixed research it is important to understand both the objective and subjective views of reality. Although it is important not to be biased or affect the phenomenon under investigation, it is also so important to understand the social actors' point of view.

Despite all these opinions, many researchers have argued that scholars did not give much attention to the ontological issue in pragmatism. Morgan (2007) has mentioned that pragmatists refuse the top-down prevailing of the ontological assumptions and believe that epistemological and methodological issues should be separated from ontology. Also, Pratt (2016) has criticized pragmatic scholars for focusing on pragmatism as epistemology and methodology, while ignoring pragmatism as ontology. Moreover, Lohse (2017) has referred to the same meaning in what he has called the "anti-ontological pragmatism" that rejects ontological stances as underground for doing research. Similarly, Hathcout and Meixner (2017) have argued that pragmatism has created "anti-philosophical" attitude avoiding discussing reality issues while seeking to maximize research benefits through the notion "what works". In their opinion, despite all researchers' trails to define the pragmatic philosophy, it is not clear how pragmatism guides the social inquiry process which created an "anything goes" attitude.

The researcher agrees to these opinions and argues that the ontological position of pragmatism still not clear until the moment. Ignoring or avoiding this issue or even simply claiming that a pragmatic researcher uses both the quantitative and qualitative ontological stances is a great point of weakness that prevents pragmatism from 
evolving into a coherent paradigm. Pragmatism is deeply in need of a clear ontological stance that justifies how a pragmatic researcher can switch between two opposite ontological positions to fulfil his research purposes, in other words, in which cases and under which circumstances a pragmatic researcher should choose to be objective or subjective.

In order to allow pragmatic researchers to view and use multiple ontological positions, pragmatism should flow from an ontological stance that is located in the middle of the objectivity-subjectivity continuum. The researcher conceptualizes this ontological stance as the reality cycle.

The reality cycle is based on the idea of the existence of one reality and multiple perceptions of this reality in the social actors' minds. According to the reality cycle, there is only one reality exists in a certain context at a certain point of time. Reality depends on the context to exist and continue existing, which means that changing the context changes the reality and the existence of multiple contexts means the existence of multiple realities. However, this reality is perceived differently by the social actors which causes reality to change in a continuous process that goes as follows: reality is perceived by humans or social actors differently, humans' perceptions of reality control their behaviours, interactions among these behaviours construct a new context over the time, and constructing a new context generates a new reality. Although these changes in the context happen continuously it does not have an immediate practical effect, however, it creates notable changes in reality after a considerable period of time, exactly like the ageing process of a human being that happens every second but it may take years to be notable. In consequence, the reality cycle adopts a practical pragmatic point of view assuming that reality is stable most of the time and changes periodically. "The reality cycle" is illustrated in figure 1.

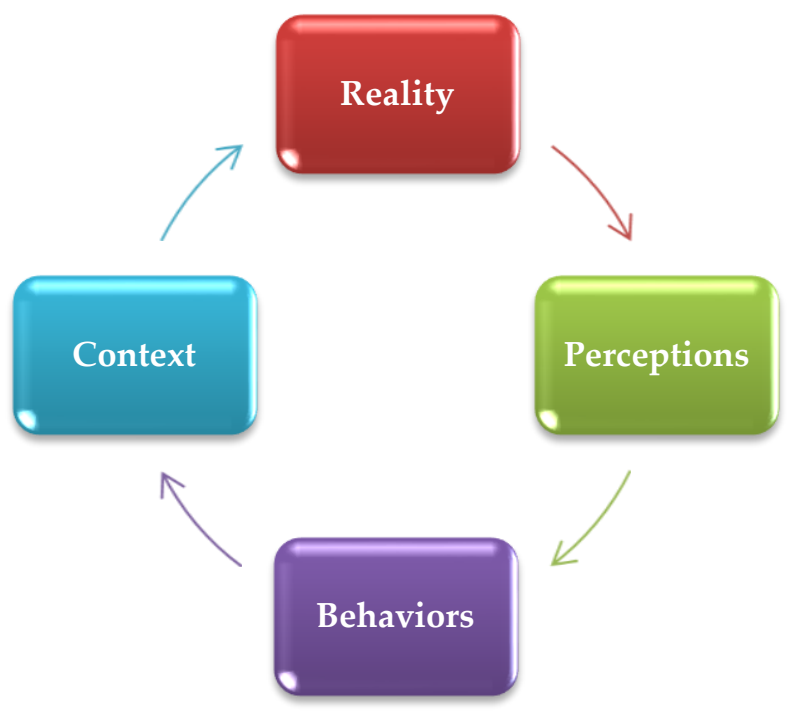

Figure 1 . The reality cycle

The reality cycle assumptions allow the pragmatic researcher to switch between the two views of the one external reality and the multiple perceptions of reality in social actors' minds and thus between the quantitative and qualitative research approaches and methods.

First, assuming reality is stable most of the time, the reality cycle allows the pragmatic researcher to adopt the one realty view and use the quantitative approach to test a theory about reality. Having a theory to be tested means that we have minimum knowledge about the phenomenon under investigation and the context containing this phenomenon, which allows us to develop variables to be measured and hypotheses to be tested. In this case, the pragmatic researcher describes the reality temporarily in low-like generalizations, which is practical enough to match the pragmatic notion "what works".

Second, as the reality cycle also assumes that reality changes periodically, the pragmatic researcher takes into account that these generalizations are going to be obsolete when the context changes, which requires to pay close attention and review the theories of social sciences as much as necessary to make sure it is still valid and representing the truth. In case the theory became obsolete a pragmatic researcher needs to develop the current 
theory or create a new one. This may also happen when we conduct research in a new context or face a new phenomenon. Then we face a situation where we do not have the minimum knowledge we need; we have no theory to be tested and no idea about the variables that could be affecting or explaining this phenomenon. In these cases, a pragmatic researcher is allowed to use a qualitative approach to examine the social actor's perceptions about reality. Examining social actor's perceptions will provide a deep understanding of the context generating the reality and help the researcher to develop a new theory or create major developments in the current one. Once the theory is developed the pragmatic researcher can switch back to the one reality position and test the theory through quantitative research.

As it could be misunderstood the researcher needs to stress two critical points. First, the reality cycle is built on the existence of one reality in a certain context and multiple perceptions of this reality in social actors' minds not the existence of multiple realities based on researchers' construction of reality. Researchers are seeking the truth and the truth is "what works", this single truth that works is what a pragmatic researcher is looking for. The purpose of using qualitative methods is not to construct the reality as a unique interpretation of the researcher but to discover the reality, this single truth that already exists, through investigating the social actors' perceptions. Qualitative methods help the researcher to gather the information that will be analysed to get a deep understanding of the phenomenon and create a theory that will be tested through quantitative research. Second, the reality cycle does not support the claim that qualitative research is unscientific and therefore it should be validated with quantitative scientific research. On the contrary, the reality cycle asserts that every research approach has a role in the theory development process. We only tend to confirm the qualitative research results with quantitative research because it provides a simplified view of reality that is more appropriate for the practical goals of pragmatism and the notion "what works".

In that sense, the reality cycle supports both the sequential and parallel mixed research. First, it provides the guidance researchers need by explaining the basis on which a pragmatic researcher can switch between being objective or subjective which supports the sequential mixed research approaches. Second, it asserts that both quantitative and qualitative methods are studying the same phenomenon from two different positions, either directly while testing a theory describing the phenomenon or indirectly through investigating social actors' perceptions that create the context containing this phenomenon. Understanding that both types of methods are studying the same phenomenon from two different positions justifies the parallel mixed research approach and makes triangulation and cross-validation totally logical.

\subsection{The Epistemological Stance: The Double-Faced Knowledge}

Although pragmatism is well defined from the epistemological point of view in the sense that a pragmatic researcher can use whatever research method works to meet his research objectives based on its practical value and regardless of its underlying philosophy, this separation between ontology and epistemology is a continuous source of criticism. Therefore, the researcher believes in an epistemological point of view that directly flows from the reality cycle stance. This epistemological position is conceptualized as the double-faced Knowledge.

According to the double-faced knowledge, any type of knowledge can be seen as observable or unobservable based on the ontological position of the researcher not on the nature of knowledge itself. In consequence, the pragmatic researcher accepts both types of knowledge based on his instantaneous ontological position and his main concern is to choose the right research method that is the most appropriate to this ontological position and best serves his research objectives.

In order to clarify this concept, the researcher raises a very critical inquiry; do quantitative research methods used by positivists in social sciences actually deals with observable knowledge in the same sense of natural sciences? And similarly, do qualitative research methods used by interpretive researchers actually deal with unobservable knowledge?

Knowledge in social sciences is completely different than knowledge in natural sciences as most of it is not observable by nature. Most of the variables that we deal with such like feelings, beliefs, attitudes, and intentions are not outside us to be measured in the same way of measuring objects in natural sciences, it has to be expressed to be understood (Ma, 2012). looking at the non-experimental quantitative methods such like survey, it does not address an observable knowledge, it is mostly dealing with unobservable mental variables exactly like the unstructured or semi-structured qualitative interviews, the only difference is that quantitative researchers use quantitative techniques to deal with this source of knowledge which limits human responses to a certain number of structured answers in order to be able to measure it. Quantitative researchers claim that they only accept observable measurable knowledge, although the variables they are dealing with are not observable by nature and the measuring process in the social sciences never enjoys the same degree of validity and reliability provided in 
natural sciences.

Similarly, describing social reality through qualitative observation to human behaviours is not dealing with unobservable knowledge; it is dealing with observable human actions exactly like quantitative experimental research with the difference that qualitative researchers are interested in the detailed descriptions of these actions and the meanings attached to it, while quantitative researchers deal with the same source of knowledge in a structured quantitative manner that aims at simplifying the situation into variables and relationships.

In total, this means that the quantitative and qualitative researchers' claim that they can only accept either the observable or unobservable knowledge is just a difference in their points of view not because the knowledge is observable or unobservable by nature. As a matter of fact, both quantitative and qualitative researchers deal with the same sources of knowledge all the time, however, every group of researchers use the type of methods that is compatible with their paradigm's assumptions and goals.

For pragmatic researchers, and based on the reality cycle stance that accepts both the existence of one reality and the importance of social actors' perceptions of this reality, sometimes we have the goal of describing reality in like-law generalizations for practical benefits and other times we are examining social actors' perceptions for more detailed and deep understanding of this reality. So, we can deal with all sources of knowledge using the suitable type of methods that help us reach our research objectives.

In that sense, the double-faced knowledge stance creates a link between the ontological and epistemological pragmatic assumptions. Based on the reality cycle ontological stance researchers switch between being objective and subjective and in consequence switch between accepting observable and unobservable knowledge. This means that the double-faced knowledge overcomes the criticism that pragmatic researchers have created "anti-philosophical" attitude in favour of the practical benefits of the research methods they use. In addition, it is compatible with the notion "what works" from the epistemological and methodological points of view.

\subsection{The Axiological Stance: The Necessary Bias Principle}

Based on the former ontological and epistemological stances that allow us to deal with the observable or unobservable knowledge using both quantitative and qualitative methods, a pragmatic researcher should be biased only by the degree necessary to enhance his research and helps to answer his research questions. This is what the researcher calls the necessary bias principle.

Unlike natural sciences, the phenomenon in social sciences is meaningful prior to the research process. This pre-understanding or pre-judgment forms the basis of both quantitative and qualitative research and directs researchers' choice of research questions and variables (Ma, 2012). As this pre-understanding is unavoidable, the researcher believes that there's nothing can be called value-free or bias-free research not even from positivism point of view.

This is compatible with the opinions of many researchers who have referred to the effect of quantitative researchers' values on their research. Saunders et al. (2009), Johnson and Onwuegbuzie (2004), and Ma (2012) have mentioned that it is impossible to be completely free of our own values and experiences. Positivists' values affect their choices of the research topic, objectives, data collection, analysis and interpretation. Moreover, Weber (2004) added that, as a positivist, he is aware that variables he chooses in his research reflect his pre-understanding of reality and the main purpose of collecting and analysing data is to evaluate this pre-understanding. These opinions mean that all decisions made by positivists through all stages of research are affected by the researcher's values, personal experience and perceptions about the phenomenon under investigation. Moreover, even if positivists managed to eliminate their bias, measures they use do not enjoy a hundred per cent degree of validity or reliability and will never provide the same measuring accuracy as in natural sciences.

From the other side, the value-laden principle in qualitative research does not mean that qualitative research is unscientific research manipulated by the researchers. Ma (2012) referred to the concept of "shared reality", it is what gives meanings to our communicative actions and makes it understandable, this reality is what we want to discover in qualitative research. Having a previous knowledge or perceptions should only enrich the qualitative research by helping the researcher to add more insights and discover more sides of this shared reality not manipulating research results in a certain direction.

In total, the researcher argues that regardless of what research paradigm, there will be some sort of unavoidable bias. However, researchers' values, experiences, beliefs and ideas should be a source of reinforcing research not to be an obstacle in the way of reaching the truth. In consequence, a pragmatic researcher should focus on his research objectives and use his values and experiences in a way that serve these objectives and enhance his 
research results. In other words, he should be biased only by the necessary degree to meet the research requirements.

It is very important here to assert that "the necessary bias principle" does not mean that any form of bias is acceptable. The unacceptable bias happens if the researcher directed his research results in a predetermined way to reflect certain values he believes in. For example, regarding the ethical or religious values, it is acceptable to affect the researcher choice of some research topics or questions over the others, such as the case in the transformative research or Islamic finance, however, it is not acceptable that these values' effects extend to the further stages of research or affect the research results.

\section{Conclusion}

The main purpose of the present research is to overcome the criticism that pragmatic researchers have created "anti-philosophical" or "anything goes attitude". The researcher challenges the quantitative-qualitative paradigmatic differences in order to create distinctive philosophical stances for pragmatism, instead of just claiming that pragmatists can use both quantitative and qualitative philosophical assumptions. This contribution is an attempt to move pragmatism from a philosophy that merely depends on epistemology and methodology to a coherent, integrated paradigm with clear philosophical stances that lie in the middle of the quantitative-qualitative paradigms continuum. The researcher suggests that pragmatism has the ability not only to provide the philosophical justification for the mixed research approach but also it opens all possible options in front of researchers, what can make it prevail over all other research philosophies.

The ontological, epistemological and axiological stances for pragmatism has been conceptualized in a way that combines both quantitative and qualitative paradigms' points of view as two integrated, not conflicting, philosophies. First, the reality cycle is the ontological stance that is based on the existence of one reality in a certain context at a certain point of time and multiple perceptions of this reality in the social actors' minds. Social actors' perceptions of reality control their behaviours which causes changes in the context and in consequence in reality. As reality changes, the pragmatic researcher can switch between the two positions of the one reality or the multiple perceptions of this reality. Second, the epistemological stance, the double-faced knowledge, suggests that quantitative and qualitative researchers' claim they can only accept either the observable or the unobservable knowledge is just a difference in their points of view not a difference in the nature of knowledge itself. Thus, any type of knowledge can be seen as observable or unobservable based on the instantaneous ontological position of the pragmatic researcher. Finally, the necessary bias principle is the axiological stance that permits the researcher to be biased only by the degree necessary to enhance his research and helps to reach his research objectives. These three philosophical stances need to be examined, discussed, evaluated and developed by future research.

\section{References}

Antwi, S. K., \& Hamza, K. (2015). Qualitative and quantitative research paradigms in business research: A philosophical reflection. European Journal of Business and Management, 7(3), 217-225. Retrieved from https://www.iiste.org/Journals/index.php/EJBM/article/view/19543

Barnes, B. R. (2019). Transformative mixed methods research in South Africa: Contributions to social justice. In S. Laher, A. Fynn, \& S. Kramer (Eds.), Transforming research methods in social sciences: Case studies from South Africa (pp. 303-316). Johannesburg: Wits University Press. https://doi.org/10.18772/22019032750.24

Baŝkarada, S., \& Koronios, A. (2018). A philosophical discussion of qualitative, quantitative, and mixed methods research in social science. Qualitative Research Journal, 18, 2-21. https://doi.org/10.1108/QRJ-D-17-00042

Betzner, A. E. (2008). Pragmatic and dialectic mixed method approaches: An empirical comparison (Doctoral dissertation, The University of Minnesota, Minnesota, USA). Retrieved from http://hdl.handle.net/11299/46961

Biddle, C., \& Schafft, K. A. (2015). Axiology and anomaly in the practice of mixed methods work: Pragmatism, valuation, and the transformative paradigm. Journal of Mixed Methods Research, 9, 320-334. https://doi.org/10.1177/1558689814533157

Bryman, A., \& Bell, E. (2007). Business research methods (2nd ed.). Oxford; New York: Oxford University Press.

Cameron, R. (2011). Mixed methods research: The five P's framework. The Electronic Journal of Business Research Methods, 9, 96-108. Retrieved from http://www.ejbrm.com/volume9/issue2/p96 
Creswell, J. W. (2014). Research design: Qualitative, quantitative, and mixed methods approaches (4th ed.). Thousand Oaks, CA: Sage publications.

Denscombe, M. (2008). Communities of practice: A research paradigm for the mixed methods approach. Journal of Mixed Methods Research, 2, 270-283. https://doi.org/10.1177/1558689808316807

Dieronitou, I. (2014). The Ontological and epistemological foundations of qualitative and quantitative approaches to research. International Journal of Economics, Commerce, and Management, 2(10). Retrieved from http://ijecm.co.uk/volume-ii-issue-10/

Fetters, M. D., \& Molina-Azorin, J. F. (2017a). The journal of mixed methods research starts a new decade: Principles for bringing in the new and divesting of the old language of the field. Journal of Mixed Methods Research, 11, 3-10. https://doi.org/10.1177/1558689816682092

Fetters, M. D., \& Molina-Azorin, J. F. (2017b). The journal of mixed methods research starts a new decade: The mixed methods research integration trilogy and its dimensions. Journal of Mixed Methods Research, 11, 291-307. https://doi.org/10.1177/1558689817714066

Ghiara, V. (2019). Disambiguating the role of paradigms in mixed methods research. Journal of Mixed Methods Research, Online first article: Published 2 January 2019. https://doi.org/10.1177/1558689818819928

Glogowska, M. (2011). Paradigms, pragmatism, and possibilities: Mixed-methods research in speech and language therapy. International Journal of Language and Communication Disorders, 46, 251-260. https://doi.org/10.3109/13682822.2010.507614

Goldkuhl, G. (2008, December). What kind of pragmatism in information systems research? Paper presented at AIS SIG Prag Inaugural meeting, Paris, France. Retrieved from

https://www.semanticscholar.org/paper/What-kind-of-pragmatism-in-information-systems-Goldkuhl/d6431e 41eec4c16ce104bde9404fb87ec39c4fa0

Goldkuhl, G. (2012). Pragmatism vs. interpretivism in qualitative information system research. European Journal of Information System, 21, 135-146. https://doi.org/10.1057/ejis.2011.54

Greener, S. (2008). Business research methods. Ventus Publishing. ApS. Retrieved from http://gent.uab.cat/diego_prior/sites/gent.uab.cat.diego_prior/files/02_e_01_introduction-to-research-metho ds.pdf

Hall, R. F. (2013). Mixed methods: In search of a paradigm. In T. Le, \& Q. Le (Eds.), Conducting research in a changing and challenging world (pp. 71-78). New York: Nova Science Publishers Inc.

Hathcoat, J. D., \& Meixner, C. (2017). Pragmatism, factor analysis, and the conditional incompatibility thesis in mixed methods research. Journal of Mixed Methods Research, 11, 433-449. https://doi.org/10.1177/1558689815622114

Johnson, B., \& Christensen, L. (2012). Educational research: quantitative, qualitative, and mixed approaches (4th ed.). Thousand Oaks, CA: Sage publications.

Johnson, R. B., \& Onwuegbuzie, A. J. (2004). Mixed methods research: A research paradigm whose time has come. Educational Researcher, 33(7), 14-26. https://doi.org/10.3102/0013189X033007014

Johnson, R. B., Onwuegbuzie, A. J., \& Turner, L. A. (2007). Toward a definition of mixed methods research. Journal of Mixed Methods Research, 1, 112-133. https://doi.org/10.1177/1558689806298224

Jonker, J., \& Pennink, B. (2010). The essence of research methodology: A concise guide for master and PhD students in management science. Berlin: Springer.

Lohse, S. (2017). Pragmatism, ontology, and philosophy of the social sciences in practice. Philosophy of the Social Sciences, 47, 3-27. https://doi.org/10.1177/0048393116654869

Ma, L. (2012). Some philosophical considerations in using mixed methods in library and information science research. Journal of the American Society for Information Science and Technology, 63(9), 1859-1867. https://doi.org/10.1002/asi.22711

Mitchell, A. (2018). A review of the mixed methods, pragmatism and abduction techniques. The Electronic Journal of Business Research Methods, 16, 103-116. Retrieved from http://www.ejbrm.com/volume16/issue3/p103

Mkansi, M., \& Acheampong, E. A. (2012). Research philosophy debates and classifications: Students' dilemma. The Electronic Journal of Business Research Methods, 10, 132-140. Retrieved from 
http://www.ejbrm.com/volume10/issue2/p132

Molina-Azorin, J. F. (2016). Mixed methods research: An opportunity to improve our studies and our research skills. European Journal of Management and Business Economics, 25, 37-38. https://doi.org/10.1016/j.redeen.2016.05.001

Morgan, D. L. (2007). Paradigms lost and pragmatism regained: Methodological implications of combining qualitative and quantitative methods. Journal of Mixed Methods Research, 1, 48-76. https://doi.org/10.1177/2345678906292462

Pratt, S. F. (2016). Pragmatism as ontology, not (just) epistemology: Exploring the full horizon of pragmatism as an approach to IR theory. International Studies Review, 18, 508-527. https://doi.org/10.1093/isr/viv003

Sale, J. E. M., Lohfeld, L. H., \& Brazil, K. (2002). Revisiting the quantitative-qualitative debate: Implications for mixed method research. Quality and Quantity, 36, 43-53. https://doi.org/10.1023/A:1014301607592

Saunders, M., Lewis, P., \& Thornhill, A. (2009). Research methods for business students (5th ed.). Harlow, Essex: Person Education Limited.

Shannon-Baker, P. (2016). Making paradigms meaningful in mixed methods research. Journal of Mixed Methods Research, 10, 319-334. https://doi.org/10.1177/1558689815575861

Weber, R. (2004). Editor's Comments: The rhetoric of positivism versus interpretivism: A personal view. MIS Quarterly, 28(1), Iii-Xii. https://doi.org/10.2307/25148621

Yvonne, F. M. (2010). Doing mixed methods research pragmatically: Implications for the rediscovery of pragmatism as a research paradigm. Journal of Mixed Methods Research, 4, 6-16.

https://doi.org/10.1177/1558689809349691

\section{Copyrights}

Copyright for this article is retained by the author(s), with first publication rights granted to the journal.

This is an open-access article distributed under the terms and conditions of the Creative Commons Attribution license (http://creativecommons.org/licenses/by/4.0/). 